\title{
IOM Smart Health Line: Giving back
}

\author{
Prof. Pradeep Vaidya
}

Institute of Medicine (IOM) had a program called "IOM to heath post" when there were no televisions or mobiles. This was conducted through radio and in this program; medical queries of health personnel from health posts situated at the remotest areas of the country were answered. This used to be a popular program and there used to be lot of questions.

This used to be very important to the medical personnel because they got guidance of the specialists and it helped them to decide treatment strategies for their patients. This made them feel secure and connected to people outside the confinement of their small village. It also showed that somebody cared. More importantly, however diminutive it may be, it helped IOM contribute something back to the remotest part of the community.

IOM being one of the prestigious institutes of the country has more than 24 clinical specialties. Although lot of people visit IOM's Tribhuvan University Teaching Hospital for their medical diseases there are many millions more who are not able to do so, due to either the finance or difficulty in travelling from a remote village. Any major disease would obviously require a visit to a hospital but there may be so many diseases that can be helped by even long distance consultation. This may not be the best method but for a dark room even a small candle light can shed enough light.

In our neighboring country, Bangladesh, there is a system called 'Gramin phone consultation', which helps people from the rural areas with their medical questions by mobile phones. It seems to be a very popular program and has been helpful to lot of people from villages.

There are lots of difficulties in Nepal, but despite these difficulties, one of the fields that have developed fast and to a great extent is the telecommunication and Information

Technology. This has opened doors that one would not even think of a decade or even five years ago. For example, communication with mobiles, video conferencing from the rural areas.

Smart phone is a mobile company with the mandate to provide mobile service to the rural areas, especially in remote areas where a health post would be a three to five days walk. They have nearly a hundred thousand and increasing number of people using their services.

IOM and Smart phone with their specialty got together with a plan to provide medical service to these underprivileged people at these far-flung areas. From the new Nepali year, IOM with Smart phones is embarking on the project together called IOM Smart Health line where any smart phone subscriber could call a particular number and get answers/ guidance on any medical queries he/she may have from a qualified medical doctor. In the beginning it will be only on week days and between the hours of nine to five. Once the program gets established properly then the plan is to provide the service all the time.

This is just the beginning, very soon with the help of the government; all the staffs of the rural health post including the government auxiliary health worker can be provided with a smart phone so that they may be able to consult about any medical problems. Once the program is settled, then it can also join with other mobile providers to provide medical consultation to anybody requiring it. The other option is also to provide video conferencing. There are immense possibilities and we can tap on it as appropriate.

This way for once, instead of always complaining of what we lack, we can use what we have and still help our country people and give back even if it is little. 